\title{
Business Intelligence in Telecoms Industry: A Service Oriented Approach
}

\author{
Tanko Ishaya and Musiliudeen Folarin \\ The University of Hull, Scarborough Campus \\ United Kingdom
}

\section{Introduction}

Mobile market is becoming saturated and competitive in telecoms industry. As a result, these organizations are becoming more and more conscious about the advantages of data and information kept in their organization, the need to integrate these large volumes of data and to utilize these information to support the quality of their decision-making, in order to stay at a competitive advantage and to increase profit (Wu et al, 2007; Pareek, 2006). The profitability of these industry is clearly linked to its subscriber base which again depends on number of active customers, duration of calls made by customers, quality of service, price as compare to others, and ability to satisfy customers (Pareek, 2006). To properly utilize the relationships between all the profitability attributes, there is a clear demand for quality Business Intelligence (BI) (Wu et al, 2007; Pareek, 2006). BI is the combination of business processes with the use of IT Systems such as DWs, Data Marts, Metadata Data Mining, ETL, Query and Reporting Software, OLAP, and Visualization (Kudyba and Hoptroff, 2001; Pareek,2006) to support decision-making in an organization.

However, studies have shown that many researchers view BI from different perspectives. For example, Power (2003) considers BI as a data driven decision support system while others such as Rus and Toader (2008), and Kulkarni et al (2010) considered BI as strategic information system capable of providing actionable information through a centralized data repository, sourced from numerous sources, transformed into meaningful information via BI analytical tools, to facilitate business insights leading to informed decisions. Ishaya et al. (2007) shared similar view with Rus and Toader (2008) and further classified Information System in an organization into two broad categories: Operational Support Systems (OSS) which are systems that supports day-to-day business operational data and Decision Support Systems (DSS) which are systems that support decision-making. Ranjan (2009) defined BI as a way and method of improving business performance by making actionable information available for decision makers in an organization. BI is also defined as "the communication facility serving the conduct of a business, the notion of intelligence is the ability to apprehend the interrelationship of presented facts in such a way as to guide action towards a desired goal" (Rus and Toader, 2008). Hence, BI can be define as a process and methods of improving decision-making through a combination of business processes and effective utilization of IT to integrate data and information from various OSS into DWs, using data mining to analyze the data, and generating high-level report in a timely and user friendly manner for the decision makers in an organization. 
BI assists corporate managers and decision makers to make relevant, accurate, timely and smart decision in an organization and thus lead to increase in productivity and profitability of an organization (Gordon et al, 2006; Ranjan, 2009). BI is a field of building "information that is conclusive, fact-based, and actionable"(Pareek, 2006). Therefore, BI expose the importance of data and information kept by various organizations, which can be used to help in accurate and efficient decision-making based on the facts rather than human reasons (Ishaya et al, 2007). The competitive forces common in the world of business today require a business organization to operate efficiently and productively in order to maintain and support market share, profitability and shareholder values (Atre, 2003; Madnick et al, 2009). BI use traditional Extracts, Transform and Load (ETL) for data integration from Operational Support System (OSS) such as CRM, Decision Support System (DSS), Supply Chain Management (SCM), Enterprise Resource Planning (ERP), and E-business application (Pareek, 2006), which involve complex rule and long-running business processes during business downtime and which may span days as emphased in Gordon et al(2006). Current implementation of BI in telecoms organization is still based on traditional approach to data integration, which is static in nature. This approach may not meet up with constantly changing analysis required to support decision-making due to its static nature and direct end-to-end BI tools (Wu et al, 2007). Million of Call Details Record (CDR) are being generated daily and as services providers add new services to ensures customer satisfaction, customer's data will continue to grow exponentially, which can be difficult to analyze at a reasonable time and cost (Gordon et al, 2006; Ranjan, 2009). Therefore, there is need for a Service Oriented (SO) approach to BI in order to provide real-time data analysis. The SO approach will also provide an open, interoperable and potentially collaborative means of proving BI (Berthold et al, 2010).

This chapter presents an investigation into the integration and analysis of data from CRM and CDR of Telecoms operators using SO approach to assist the organization in making real-time and accurate decision about the customer tariff plan to ensure customer satisfaction which in return can lead to increase in profit.

The research has investigated the use of SO approach to BI in Telecoms organizations towards providing real-time and accurate decision support about customer tariff plan in order to ensure customer satisfaction. The chapter presents:

- A thorough review of current approaches/technologies to BI with telecoms industry and data sources -such as CDR, Billing system and CRM

- The development of Service Oriented Business Intelligence (SOBI) architecture based on an analysis of existing architectures/models and customer requirements that were captured through questionnaires. The architecture integrates integrate data from heterogeneous data sources of these organizations.

- Development of a SOBI prototype system that simulates the basic operation of a typical telecoms organization.

- An evaluation of the architecture and potential effectiveness using the implemented prototype

\section{A background to BI within telecoms}

Advancement in the use of information technology (IT) over the past 50 years to collect, keep, extract, analyze and communicate data and information (Kudyba and Hoptroff, 2001) 
has lead business organizations through an era of OSS (Pareek, 2006). With these OSS, business organizations are able to keep lots of data about customers and daily operation and they now want to turn these data into actionable information. Since there are different perspectives to $\mathrm{BI}$, there are also differing challenges of $\mathrm{BI}$ applications between organisations. The table below presents an analysis of some of the challenges that different industries face in implementing BI applications.

\begin{tabular}{|l|l|l|}
\hline \multicolumn{1}{|c|}{ Industry } & Application & \multicolumn{1}{c|}{ Challenge } \\
\hline \multirow{2}{*}{ Telecommunication } & CRM, DSS & $\begin{array}{l}\text { Legal Issues (Griffin, 2003; Kudyba and } \\
\text { Hoptroff 2001). } \\
\text { Ethical Issues (Griffin, 2003). } \\
\text { Collaboration Business Platforms (Griffin, } \\
\text { 2003; Atre, 2003; Johnstone and Wong, 2008). } \\
\text { Improper Implementation (Ishaya and } \\
\text { Rigneau, 2007; Levine, 2002). } \\
\text { Minimization of time (Griffin, 2003). }\end{array}$ \\
& & $\begin{array}{l}\text { Data Quality (Madnick et al, 2009; Ishaya and } \\
\text { Julian 2007; Ishaya and Rigneau, 2007) }\end{array}$ \\
\hline Construction & DSS & $\begin{array}{l}\text { Collaboration Business Platforms (Griffin, } \\
\text { 2003; Atre, 2003). }\end{array}$ \\
\hline Retail Sale & CRM, DSS & $\begin{array}{l}\text { Data Quality (Madnick et al, 2009; Ishaya and } \\
\text { Julian 2007; Ishaya and Rigneau, 2007). } \\
\text { Improper Implementation (Ishaya and } \\
\text { Rigneau, 2007; Levine, 2002) }\end{array}$ \\
\hline E-Commerce & CRM & $\begin{array}{l}\text { Ethical Issues (Witten and Frank, 2005) } \\
\text { Legal Issues (Witten and Frank, 2005) }\end{array}$ \\
\hline Insurance & DSS &
\end{tabular}

Table 1. BI Challenges in various Industries

As can be seen from Table 1 above, collaborative business platforms is a fundamental challenge as also identified in Bethold et al(2010) that require investigating within telecoms industry. This section presents a review of BI, implementation of BI within Telecoms industry, and data sources use for data warehouses (DWs) and BI in Telecoms industry and an analysis of the data sources within the industry.

\subsection{A review of current approaches to $B I$ in telecoms industry}

Application of BI in Telecoms Industry has been focused mainly on customer management, fraud management, knowledge discovery and key performance indicators (Christine normile 2006). Each application has its own process and the processes are often automated in the Telecoms industry. BI combines business processes with IT systems to support decision-making in an organization. The IT systems used in BI such as DWs, OLAP, and Reporting have their own processes and combination of these processes made up the processes of BI. Business processes in $\mathrm{BI}$ are business rules defined by each Telecoms organization base on the business requirement and objectives. If for instance, the objective of Telecoms Company is to manage customers, then customer satisfaction becomes the business requirement and as a result, a set of rules are developed to define the processes required to achieve the requirement. 
The process of CRM in Telecoms industry involves three steps, which are customer identification, understanding, and interaction as shown in Figure 1 below.

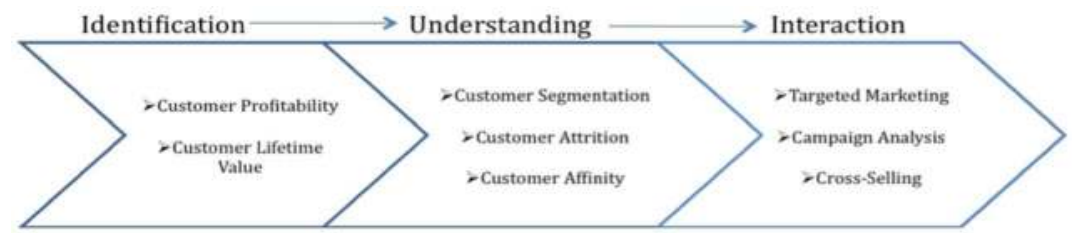

Fig. 1. Process of CRM in telecoms (Normile, 2006)

The following sections provides a brief description of the main components:

\subsubsection{Identification}

Customer identification is very important to Telecom operators and it starts from counting the number of subscriber base via a unique identification MSISDN and to identify the most profitable and potential profitable customers in the future. In the past, Telecom operators were more concerned about the number of subscribers with a simple view that the more the subscribers the more their turn over until recently when the telecoms operators started applying BI before they discover many unknowns such as the differences in the contribution of each subscriber (Normile, 2006). Hence, they need to define business rule to identify customers who are the most profitable among their customer base and who are the less profitable. These set of business rules help the company to keep the profitable customer to ensure stable income while the less profitable one can also give an insight about the reasons why they are not profitable, which may be due to wrong offerings, low income or bad network in their location and so on. To determine the overall customer profitability, the operators need to calculate the costs of serving customers over a period of time and revenue realized over the same period of time (Normile, 2006).

The second attribute in the identification component is the Customer Lifetime Value (CLV), which is the value in terms of money that a telecoms operator can realize from the customer over long-term (Cunningham et al, 2004). Analysis of CLV could tell if a customer is likely to be more profitable in the future or not and a customer may also serve as reference to a profitable customer (Normile, 2006). CLV is also used to justify the cost of customer acquisition. For example, if it will cost $£ 20$ to acquire a customer and CLV is about $£ 50$, then the cost may be considered justifiable.

\subsubsection{Understanding}

In order for services or products offering to be successful, there is need for proper understanding of the needs and wants of customers. Due to large number of customers, it is always good to divide them into groups for close observation before drilling down to individual customer. Segmentation is used to segment customers with common relationships. These segments now become a unique entities and the future relationship with the segments can be tailored accordingly. Through segmentation we can identify market potential relationship between products and each customer in the segments and decisions can be made about which product is likely to be interested to the segments (Lee and Park, 2005). 
Customer affinity is also referred to as market-basket analysis and this analysis tells what segments of customer are likely to buy from a group of products. Affinity analysis is usually done using association techniques to predict the right combination of products and services for a customer or segment of customer (Normile, 2006). The last in the process of CRM is customer interaction, after identifying the type of customers and understand their usage pattern; the next step is to start interacting with the customers. Targeted Marketing, Campaign Analysis, and Cross-selling are ways of interacting with the customer (Normile, 2006).

\subsubsection{Interaction}

In targeted marketing, particular group of customer segmentation are the target and once the customer segments are identified, BI tools can be used to develop a predictive model to determine buying propensity of the segment towards both new and existing products (Normile, 2006). Campaign analysis is the analysis of impact of a promotion or marketing advertisement on a particular service or product. Market affinity and market target and knowledge of past success or failure are the prerequisites of campaign analysis (Normile, 2006). Cross-selling is way of using existing data via BI tools to gain quick insight into what could be the new products that may be requested or required by the customers so that the right offer can be made to the customers when interacting or making contact with them. Cross-selling also make used of association technique to achieve it aim (Normile, 2006). However, for this to be more effective, it is important to ensure that the data captured about customers is of quality in nature. The importance of data quality for data mining has been well discussed in Ishaya and Rigneau (2007), and Griffin (2003).

\subsection{Implementation of $\mathrm{BI}$ in telecoms industry}

The processes of BI in Telecoms Industry are usually implemented using traditional BI approaches as shown in figure 2 below.

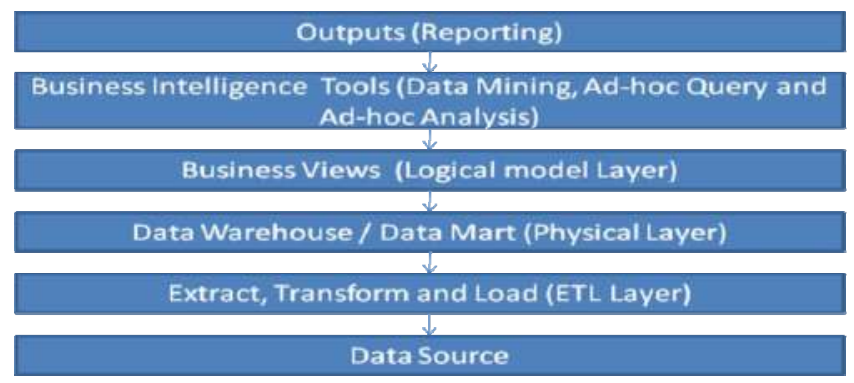

Fig. 2. Traditional Approach to BI (Wu et al, 2007)

As shown in figure 2 above, BI integrates data and information from various sdata source using the ETL process to extract transactional data, transform and upload data into DWs. After loading the data into DWs, Data mining tools such as OLAP and ad-hoc query operate on the vast amount of information stored in the DWs or Datamarts to produce business related report in a timely (near real-time) and friendly format. However, traditional approach to BI takes much longer time to process and as competition increases among 
business organizations, this approach to data integration may not meet up with constantly changing analysis needed to support decision-making due to the static and time dependent nature of DWs and direct end to end BI tools. Millions of CDRs data are being generated daily and as service providers add new services to ensures customer satisfaction, customer's data will continue to grow exponentially and it can be difficult to analyze these vast amounts of data at a reasonable time and cost (Cunningham el al, 2004). Therefore, there is the need for SO and dynamic approach to BI that would allow for flexibility, collaboration and both real-time and historic data processing and analysis of the vast amount of data and information keep in Telecoms Industry.

\subsection{An analysis of telecoms data sources}

Data sources for BI can be from OOS, external source, archived data, and information from other DWs (Ranjan, 2009). Weiss (2004) described three major data keep by telecoms organizations as CDR, Network Data, and CRM. Also Johnstone et al (2008) recognized Network Switches, Billing System and Service Records as part of data sources in telecoms organizations. The data sources for BI in Telecoms industry can be grouped into internal and external data sources as discussed in section 2.3.1 and 2.3.2 respectively. Data sources can also be classified into structure and unstructured data. The structure data referred to as data from structured databases such as relational and $\mathrm{xml}$ while unstructured data are data from text file, PDF, Web pages, and so on.

\subsubsection{Internal data sources}

The Internal data sources are data generate from OSS and examples include CDR, CRM, Billing Systems, and Service Records. CDR is generated directly from the telco's network switch. Billing System extract part of CDR, CRM and Service Records for billing purpose and merge the bill to customer via the mobile number after calculating the bill.

$\mathrm{CDR}$ is a computer record containing details of calls such as the number making the call, number receiving the call, date and time of call, call duration, call route, call type, the number charged for the call, telephone switch identity, record identity, and fault condition encountered during the call usually generated by charging system of the telephone switch. The sending telephone switches keep the CDR progressively until the end of the call, after which the Telecoms billing support system can retrieve and process the CDR for billing. Mobile CDR may contain information on more than one call type or traffic such as voice calls, Short Message Service (SMS), and other data services traffic (Johnstone and Wong, 2008). Due to valuable information contain in the CDR, Telecom operators can utilize CDR information as a data source for DWs and BI. The mediation module prepares CDR data for billing by cleaning and transforming CDRs into format that is accessible by the billing system (Johnstone and Wong, 2008). Figure 3 below shows a simple billing process and explanation on how the billing system work is provided.

All mobile calls passes through Mobile Switch Centre (MSC) for the purpose of routing and to generate, collect, and store CDR records. If the call is a local call, the call traffic is connected through MSC to a public-switched telephone network (PSTN) for a fixed-line network or directly to MSC of another mobile operator network. But in the case of International Direct Dialling (IDD) call, the traffic is routed from MSC to an international 
toll gateway (ITG) or other IDD services providers (Johnstone and Wong, 2008). The SMS CDR is being generated and recorded by Short Message Service Centre (SMSC). SMSC provides a store and forward function delivering SMS messages to the users' destination when they are available while destination mobile operator has a SMSC designated to the respective SMS message partners or SMS clearinghouse for further delivery (Johnstone and Wong, 2008). Global System for Mobile Communication (GSM), 2G General Packet Radio Service (GPRS), 2.5G GPRS and 3G GPRS offers data services and the usage of data services are recorded by GPRS Support Note (SGSN) and Gateway GPRS (GGSN). Data collected from the SGSN and the GGSN is first sent to a dedicated charging gateway (CG) before being forwarded to the mediation module. The major function of a CG is to collect CDRs from both the SSGN and GGSN, buffering and transferring CDRs to the mediation module of the billing system (Johnstone and Wong, 2008). The mediation module also contains a filtering rule algorithm. The filtering rules are a programming conditions base on the business requirements. It is very important to ensure that appropriate and complete information is delivered to the billing system for rating and necessary calculation, and the service type must be mapped accurately against the corresponding rate for accurate billing (Johnstone and Wong, 2008).

The main reasons for developing CRM is to manage customer by identifying who the customer is, understanding what customer needs and value of each customer, and interacting with them base on the information at hand. CRM also combine data from CDR, Billing System, and Customer profile and Service Record (Weiss, 2004) to give more information about the customer in order to make more accurate and stronger decision to be able to make right offer to the right customer at the right time.

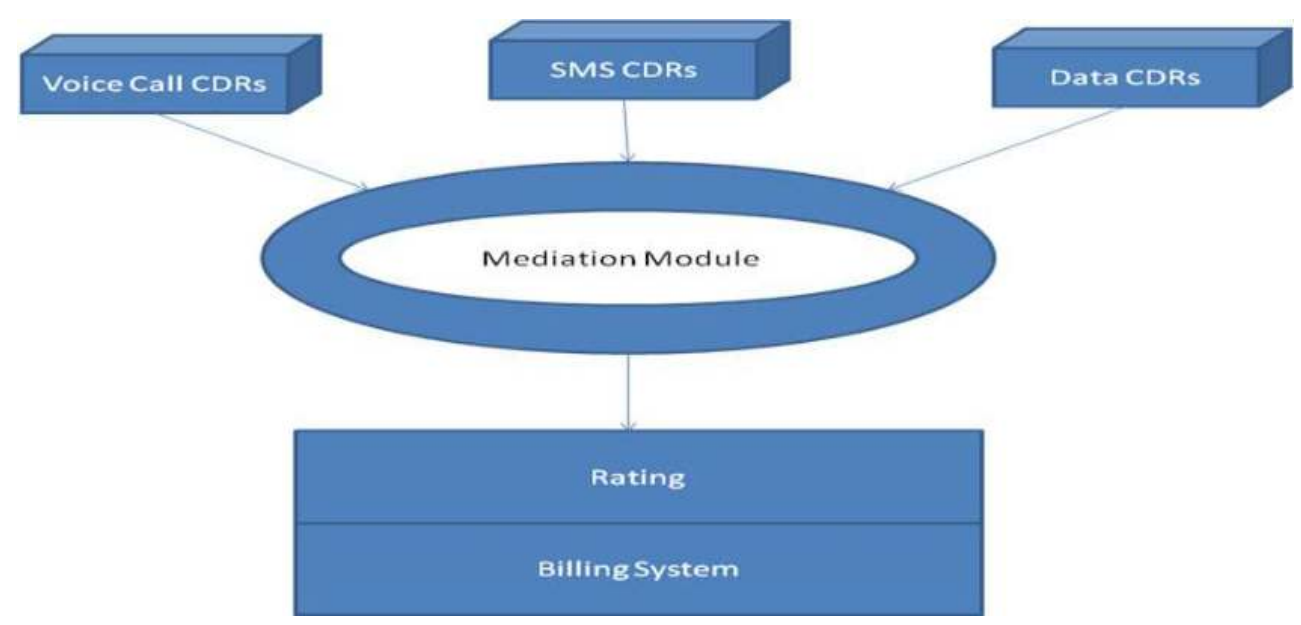

Fig. 3. Simple billing process (Johnstone and Wong, 2008) 


\subsubsection{External data sources}

The external data sources are data retrieved from external network domain such as Telecoms regulatory body and specialist vendor in the public or social network domain. Among the information retrieved from external source are customer profile information such as income, age, habits and gender and competitor's products, prices, and sales. External data sources are very expenses due to unstructured format, which need to undergo extra and complex transformation before loading into the DWs.

This section has presented a review of BI in Telecoms industry by a way of justifying a need for SOBI approach to BI in order to ensure flexible, collaborative and both real-time and historic data analysis of vast amount of data and information available within the industry. In the next section, a proposed SOBI architecture is presented and discussed.

\section{A proposed service oriented business intelligence (SOBI) architecture}

Based on the review presented in the previous section, it is clear that telecoms industries need BI that is capable of performing real-time analysis on vast amount of CDR data generated and able to analyze historical data of CDR to identify customer value and make strategic decision to retain, attract new customer, and to ensure their satisfaction towards increasing profitability. A service-oriented-architecture (SOA) is an architecture upon which different standalone services can be loosely coupled over distributed systems ( $\mathrm{Hu}$ et al, 2011). They are business-centric IT architectural approach that supports the integration of business as connected and repeatable business services. A fundamental advantage of these services is that they can communicate with each other even though each service has different underlying implementation platforms. It is therefore clear that a Service Oriented (SO) approach will provide a common, open, and interoperable solution to the problem encountered in traditional BI. While, SO approach is being used within many industries, its advantages are yet to be fully harnessed within the telecoms industry. SO can be adopted for agile and flexible applications, application-application integration, high-frequency events, real-time data analysis, reusable of services components, proper data formats and structures, and encapsulates and abstracts functionality (Gordon et al, 2006). This section presents the development of Service Oriented Business Intelligence (SOBI) architecture based on an analysis of existing architectures/models and customer requirements that were captured through questionnaires. The architecture integrates data from heterogeneous data sources of the organization.

The SOBI architectural framework intends to leverages the strengths of BI and SO while defining guiding principle to ensure that the fundamental tenets of each of the component architectures are not broken. SO allows distributed application development through interfaces capable of exchange messages through. In SOBI paradigms, BI is seen as a collection of Services such as Data Services, Transformation Services and so on, while SO is seen as a collection of data sources and event source. A service can promptly be opened "as a data source with the introduction of a simple facade layer that provides a mapping between the BI interface and interface exposed by the service" (Gordon et al, 2006). The facade layer also transforms the results set of the call from data schema used on the service bus to data format expected by the BI platform and returns the result to the caller. The section is organised as follows: Section 3.1 describes the general approach used in the 
development of the proposed architecture. Section 3.2 presents an analysis and discussion of the customer satisfaction surveys and interviews undertaken to help capture a set of user requirements for SOBI. Section 3.3 presents a review of current BI architectures, which was also used in analysing the SOBI requirements presented in Section 3.4. Section 3.5 finally presents the proposed architecture.

\subsection{Methodology}

A mixed methods approach was used in developing the SOBI Architecture. First we conducted a customer satisfaction survey via a questionnaire to capture customer requirements, and business requirement by interviewing a few Telecoms operators. Second, the requirements were used in the context of existing models. A phone simulator was developed to generate and store CDR data in OSS database since we couldn't not lay our hands on the CRM and CDR dataset from the telecoms operator that promised to provide us with such data. Samples of other data such as customer profile, tariff plan, route, rate, algorithm, route, location, and services are provided in the OOS database. A DW was developed and data and information was extracted from OSS databases to populate the DW. The customer questionnaire survey data was collected to capture requirements required for the development of the SOBI architecture. The interview was conducted with Telecoms operator to understand business rules and requirements, which form the business processes towards development of SOBI architecture.

\subsection{Customer satisfaction surveys and interviews}

An interview was conducted with two Telecoms analysts who are making use of BI report for decision-making and BI application developer analyst. One of the Telecoms analysts works with Vodafone as Online Services Senior Executive and the second works with Etisalat Nigeria as Product Specialist- Post-paid/Corporate Solutions. The first interview with Vodafone BI analyst was carried out face to face while the subsequent interview was conducted via email. Interview with Etisalat Nigeria Analyst was through email and interview with BI application developer was through online blog. During the interview, we were able to understand the type of data kept in Telecoms industry and the necessary reports needed to support decision-making process. Also, we were able to capture business rule and processes to ensure customer satisfaction, which eventually form the Telecoms operator requirement to develop SOBI architecture.

The interview conducted with Telecoms analyst also assisted in understanding the processes, which helped in the design of the questionnaire that was administered to customers. The interview with BI application developer gave us more details on how Telecoms operator system works. A questionnaire was developed and administered online by sending a link of the survey to a list of postgraduate students of the University of Hull and other individuals across UK that have volunteered to participate in the study. The questionnaire was made anonymous by making sure that personal information - such as name, telephone number, and address were not been included. This is in order to ensure that we conform to privacy law. The questionnaire was divided into sections. Section one captured some of the generic participant's personal details such as gender, age group, region and country of residence, education level, industry sector, and current position. 
Section two covers customer mobile information such as how long a customer has been using their provider's SIMcard, the name of the provider, the reasons and name of second provider for those using multiple SIMcards. Section three covers the customer usage information such as services and tariff plan used by the customer, reasons for choosing particular tariff plan and the level of their satisfaction with services, tariff plan and quality of network.

A total number of 42 customers participated in the survey with results presented in Table 2 below. A number of responses for each question in the questionnaire vary due to the option given to customers to skip or even opt out of the survey at any time, which was one of the stated conditions in the letter of consent. The analysis of the result showed that $47.6 \%$ and $52.4 \%$ are male and female who participated in the survey respectively. $66 \%$ are within the age of 18 and 30 and $90.5 \%$ are currently residing in UK and $9.5 \%$ residing in other countries. 17 out of 38 responses equivalent to $44.7 \%$ have been using their provider SIMcards for less than one year, 39.5\% have been using provider SIMcard for one to five years and $15.8 \%$ have maintained their SIMcard providers for more than five years. O2 happened to be the preferred provide for most of the participants followed by Vodafone and Orange. $20.0 \%$ used two SIMcards due to lack of variation of services, and $70.0 \%$ leave the previous provide for the current one because the current provider offer competitive tariff. 23 out of 27 responses equivalent to $85.2 \%$ of customer used their current SIMcard. $66.7 \%$ make local call every day, $25.0 \%$ make international calls every day, $46.9 \%$ make long duration call of $5 \mathrm{~min}$ and above every day, $78.1 \%$ send text messages every day, $25.0 \%$ used the internet every day, and $37.5 \%$ send or check email every day while none of them send video messages, download music and video at all on a daily basis.

\begin{tabular}{|l|c|c|c|c|c|c|}
\hline \multicolumn{1}{|c|}{ Services } & Daily & Weekly & Monthly & Yearly & Never & $\begin{array}{c}\text { No of } \\
\text { Response }\end{array}$ \\
\hline Local call & $66.7 \%$ & $15.2 \%$ & $15.2 \%$ & - & $3.0 \%$ & 33 \\
\hline International call & $25.0 \%$ & $25.0 \%$ & $12.5 \%$ & $15.6 \%$ & $21.9 \%$ & 32 \\
\hline $\begin{array}{l}\text { Make 5 min call and } \\
\text { above }\end{array}$ & $46.9 \%$ & $25.0 \%$ & $18.8 \%$ & - & $9.4 \%$ & 32 \\
\hline Text messages & $78.1 \%$ & $15.6 \%$ & $3.1 \%$ & $3.1 \%$ & - & 32 \\
\hline Video messages & - & $6.5 \%$ & $9.7 \%$ & $3.2 \%$ & $80.6 \%$ & 31 \\
\hline Internet browsing & $25.0 \%$ & $12.5 \%$ & $12.5 \%$ & - & $50.0 \%$ & 32 \\
\hline Check and send email & $37.5 \%$ & $3.1 \%$ & $12.5 \%$ & - & $46.9 \%$ & 32 \\
\hline Download music & - & $3.1 \%$ & $25.0 \%$ & $3.1 \%$ & $68.8 \%$ & 32 \\
\hline Download video & - & $3.1 \%$ & $25.0 \%$ & - & $71.9 \%$ & 32 \\
\hline
\end{tabular}

Table 2. Customer usage habit over time on various services

Customer tariff plan was also captured during the survey, with results presented in Table 3 below. 18 out of 32 responses equivalent to $56.3 \%$ of the customers are using Pas As You Go tariff plan also known as pre-paid package, $43.8 \%$ are using Contract Package also known as post-paid package while none of them were using a roaming tariff plan. The reason for choosing a particular tariff plan varies among the customers. 21 out of 28 responses equivalent to $75 \%$ choose tariff plan because they were more cheaper them, $14.3 \%$ choose a particular tariff plan because they were not aware of others, $10.7 \%$ choose tariff plan because 
of the availability of free international call, $3.67 \%$ choose a particular tariff plan because of more number of free international text, $14.3 \%$ choose tariff plan because of more number of free local call, and $10.7 \%$ choose tariff plan because of more number of free local text. The survey also captured the level of customer satisfaction on some charges and promotional offers.

\begin{tabular}{|l|c|c|c|c|c|c|}
\hline & $\begin{array}{l}\text { Strongly } \\
\text { Satisfied }\end{array}$ & Satisfied & Neutral & Dissatisfied & $\begin{array}{c}\text { Strongly } \\
\text { Dissatisfied }\end{array}$ & $\begin{array}{c}\text { No of } \\
\text { Response }\end{array}$ \\
\hline $\begin{array}{l}\text { Charges on } \\
\text { Pay As You } \\
\text { Go }\end{array}$ & $16.7 \%$ & $33.3 \%$ & $26.7 \%$ & $3.3 \%$ & $20.0 \%$ & 30 \\
\hline $\begin{array}{l}\text { Promo offer } \\
\text { on Pay As } \\
\text { You Go }\end{array}$ & $10.3 \%$ & $24.1 \%$ & $51.7 \%$ & $10.3 \%$ & $3.4 \%$ & 29 \\
\hline $\begin{array}{l}\text { Charges on } \\
\text { Contract } \\
\text { Package }\end{array}$ & - & $39.3 \%$ & $35.7 \%$ & $10.7 \%$ & $14.3 \%$ & 28 \\
\hline $\begin{array}{l}\text { Free call on } \\
\text { Contract } \\
\text { Package }\end{array}$ & $11.1 \%$ & $40.7 \%$ & $40.7 \%$ & - & $7.4 \%$ & 27 \\
\hline $\begin{array}{l}\text { Free text on } \\
\text { Contract } \\
\text { Package }\end{array}$ & $18.5 \%$ & $37.0 \%$ & $37.0 \%$ & - & $7.4 \%$ & 27 \\
\hline
\end{tabular}

Table 3. Customer satisfaction surveys

From the table above, customers are satisfied except on promotional offer where customers are neutral. These levels of satisfaction indicate where Telecom operators' analysis needs to concentrate in order to know if a customer is satisfied or not. Hence tariff plan and associated benefit need to meet the preference of the customer especially on Pay AS You Go tariff plan.

The survey further captured what will be customer next step if Telecoms operator want to use business rule of $£ 20$ usage in a month to identify loyal customer by getting the monthly usage and call of $5 \mathrm{~min}$ and above before and after asking customers how likely they are likely to make more call and used $£ 20$ in a month. 17 out of 33 responses equivalent to $51.5 \%$ of customers used $£ 20$ and above while $24.2 \%$ used less than $£ 20$ in a month. $18.8 \%$ of customers make $5 \mathrm{~min}$ call and above in a month as shown in table 1000 above. But after asking the question, the customers responses show that 14 out of 32 equivalents to $43.8 \%$ of customers are very likely to make more call, $18.8 \%$ are likely to make more call, $6.3 \%$ are not likely to make more call, and $9.4 \%$ are very unlikely to make more call if Telecoms operator is ready to reduce price on long duration call. Also, 6 out of 31 equivalents to $19.4 \%$ of customer are very likely to used $£ 20,25.8 \%$ are likely to used $£ 20,32.3 \%$ say nothing, $12.9 \%$ are unlikely to used $£ 20$, and $9.7 \%$ are very unlikely to used $£ 20$ in a month. This show that customer are willing to make more call but $£ 20$ average set by the Telecoms operator is too much for them and hence majority of customer may not be satisfied with promotional offer targeting customer with $£ 20$ usage in a month and can also be the reason why customer are not satisfied with promo offer on Pay As You Go as the case of this survey. 


\subsection{Analysis of current $\mathrm{BI}$ architecture}

As discussed, traditional BI has been designed with focus on historical data usually provided by DWs and used for strategic decision which may span days but as business activities continue to evolve there is need for multi-tier data analytics application and leverage analytics of data, event, and content (Atre, 2008; Berthold, 2010). Current approach to BI has changed beyond traditional approach (as previously discussed) in other industries such as E-commerce and a good example is Amazon.com, but Telecom Operators are just on the way to follow this trend. Telecoms Operators are now structuring OSS towards SO which in return will aid SOBI. Figure 4 below shows the component of SOBI architecture proposed by $\mathrm{Wu}$ et al. (2007).

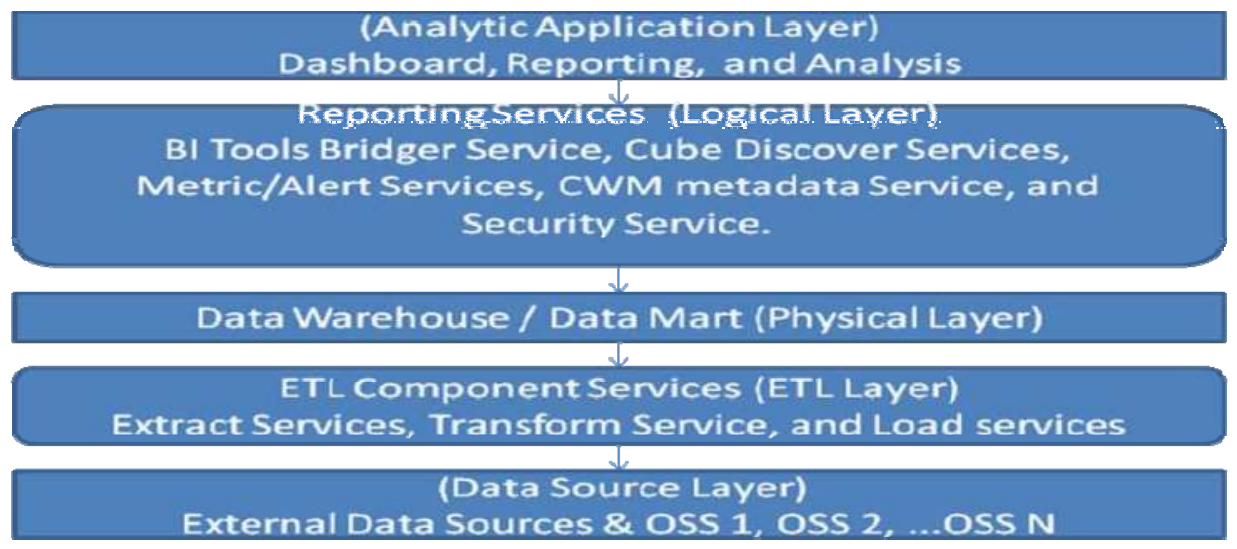

Fig. 4. Current BI Architecture (Wu et al, 2007)

$\mathrm{Wu}$ et al. (2007), described SO architecture as an improvement on the traditional BI architecture by implementing ETL Layer and Logical Layer as web component services and thus leverage $\mathrm{SO}$ and $\mathrm{BI}$ architecture.

\subsection{Requirements analysis for SOBI architecture}

Based on survey analysis, interviews and a review of related models, the following requirements were identified as fundamental in the development of SOBI architecture.

- Telecoms operators need to analyze both real-time and historical data. Real-time analysis such as registering an event on CDR record to identifying customer making long duration call and automatically billing them base on predefined tariff plan to such transactions and inform the customer about it. This can speed up decision-making process and communication. Analysis of historical data can provide adequate review of what tariff plan need to be set up, and other required services by which category or individual customer.

- Telecoms operator managers need to have a quick summary of customer satisfaction. While it is important to go through in-depth customer satisfaction analysis by the managers or the analyst, it also important to have a quick overview customer satisfaction levels. 
- Telecoms operators need to analyze customer usage pattern in various dimensions. This is important in order to understand why customers have behaved in a particular way at a particular time. For example, customers may have different calling habits depending on tariff plan, available service, time of the day, and so on. These analyses also enable the discovery of hidden behaviour, which has not been noticed in the past.

- Telecoms operators need to be able to drill down and drill up while analysing the customer usage pattern. This is also supporting requirement No. 3 mentioned above.

- Telecoms operators need BI architecture that is flexible to change in the business activities, which usually lead to changes in business requirement. Change is inevitable in business activities, therefore the more flexible to adapt to change, the more Telecoms operator will be able to survive the competitive environment.

- Telecoms operators need to ensure security of data stored in the OSS and DWs and during analysis. Security of operational data and customer information is very important to prevent loss, stolen, damage and authorise person from accessing the information while in storage or during analysis.

- Telecoms operators need to combine call details with customer profile and demographic for more accurate decision making about customer satisfaction. For example customer that is 60 years of age and above may make less calls but there may be an issue of customer dissatisfaction when customer within the age of $20-40$ is making less call.

From the customer's point of view, the following requirements were identified:

- Customers need reasonable tariffs and would wish that the tariffs were dynamically adjustable to suite individual demands, which clearly suggest a need for a personalised plan where possible.

- The customers need to be aware of current promotion and contract packages.

- Customers need quality of service

There are also a number of technical and non-technical requirements

\subsection{The proposed SOBI architecture}

The SOBI architecture was developed based on the general requirements presented in Section 3.4. The architecture is an extension of the one developed in Wu et al. (2007). Main extension is the clear emphasis on the analysis of events that should be performed on CDR data. Figure 5 below shows the developed SOBI architecture.

The SOBI architecture consists of five layers, which are Data Source Layer, ETL Layer, Physical Layer, Logical Layer, and Application Layer. Each of these layers defines a set of business processes to ensure a successful BI project. Each of the layers has been briefly described below, with a more technical insight provided in the implementation of the SOBI prototype simulator.

- Data Source Layer is the OSS database where day-to-day business transaction data are stored. Data Source Layer can also be an external source such as data from a survey company. SOBI architecture had been designed to allow analytics of events on the CDR data source in order to provide more real time analysis. The Data Source Layer stored day-to-day business activities of Telecoms operators in OOS database. In order to 
design OSS database, we need data modelling using ERM or Normalization approach to ensure that the entities in OSS database are normalized to the third normal form. This is very essential to prevent data inconsistency, data redundancy, and anomalies, which reduce the quality of data and thus make ETL process very complex and can even result into poor quality BI.

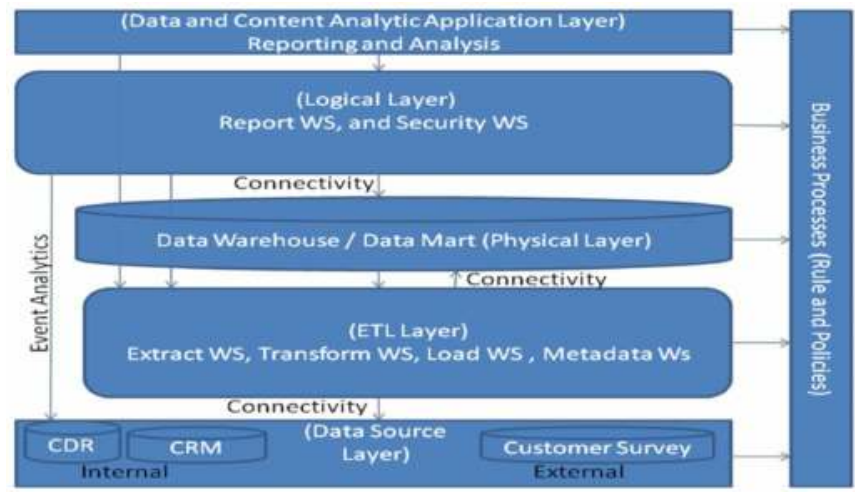

Fig. 5. SOBI Architecture

- ETL Layer consists of Extract, Transform, and Loading Services. The extract service extract all the required data from the OSS databases, transform service transform the data into a format required by the DWs while the function of loading service is to load the data and information into the DWs. The design of ETL Layer starts with the identification of the exact data that need to be extracted, the quality of the data and additional information necessary to provide complete and meaningful information. Business processes must be followed during ETL Layer design. Business processes determine when operational data is available for ETL, reformatting of OSS into a unified format, reconciling the data redundancy, and cleansing the dirty data found in the source system.

- The Physical Layer is the data repository centre of SOBI architecture and this is the layer where DWs are required to be developed. DWs have processes and architecture have been discussed in section 2. Before designing DWs, it is important to have DWs specific technical and functional requirements from the general requirements performed in section 3 .

- The Logical Layer of SOBI architecture focuses on the development of business logic. This includes appropriate activities that are required to be monitored, those that trigger other events/services, design of variable billing algorithms, tariffs, etc. This layer represents the logical view of the entire Telecoms operator data Business logic and rules regarding security, privacy, etc also falls within this layer.

- The Application Layer is the presentation layer where data are display in form of reporting tools using tables, charts, etc to aid visualization. This layer is where reporting and complex analysis are performed and rendered to the BI end user. OLAP and data mining technique will be adopted for reporting and forecasting respectively. OLAP provide summary data and information, which can also be drill down, roll up, slice and dice. Appropriate data mining techniques such as segmentation and 
exponential smoothing can be applied for specific objectives, such as the ability to predict customer satisfaction level and forecast the average usage of customer respectively.

The developed SOBI architecture will be evaluated by the prototype application, which will be discussed in the next section

\section{Development of a SOBI prototype simulator}

According to Atre and Moss (2003), BI applications require a dynamic system development approach. Since it was not possible to have access to some telecoms data, it became necessary to design a simulator to demonstrate and further reflect on the developed SOBI architecture presented in Section 3. The design of the simulator was done according to the five layers of the architecture - Data Source Layer, ETL Layer, Physical Layer, Logical Layer and Application Layer. The focus of the prototype was on the generation of CDR and CRM data, extraction, transformation and loading of the data into developed DWs. The prototype also covered report generation to demonstrate how such reports could assist Telecoms operator to analyze the customer call details over time and able to identify the relationship between tariff plan and customer usage. The prototype is limited to only call service categorise by local and international call.

\subsection{Prototype requirement analysis}

After reviewing service oriented development technologies, the prototype was design and implemented using PHP WS technology at the server side, JavaScript at the client side, and Ajax to provide dynamic interaction between the client and the server. The data source and DWs was designed and implemented using MySQL RDBMS running on Apache server with PHP installed on the server. WS was configured with SOAP extensions in the PHP library. The prototype also required sample data of CDR and CRM from Telecoms operator but a call simulator will be developed since samples data are not available.

1. The prototype is expected to allow user to simulate a call and generate the CDR data set.

2. Extract data from OSS, transform data and load into DWs.

3. Analyze customer call details to know the customer satisfaction level.

4. Identify relationship between customer usage and tariff plan.

5. Provide details information about customer in segment of the tariff plan.

The overall design of the simulator is shown in Figure 6 below.

The simulator also required the design of the data source layer in order to provide the OSS data required for the development of other layers. The entities necessary for Telecoms operator to store customer call details included Mediation, TariffPlan, TariffAlgorithm, Rate, Billing, Route, Location, Service, ServiceType, Customer, CDR, etc.

At the physical layer, a DW has been design to provide the required data repository for the SOBI prototype simulator. Before designing the DW, it was important to have the DW specific technical and functional requirements. A star schema of the DW containing a customer fact table and the associated dimensions were designed as shown in Figure 7. 


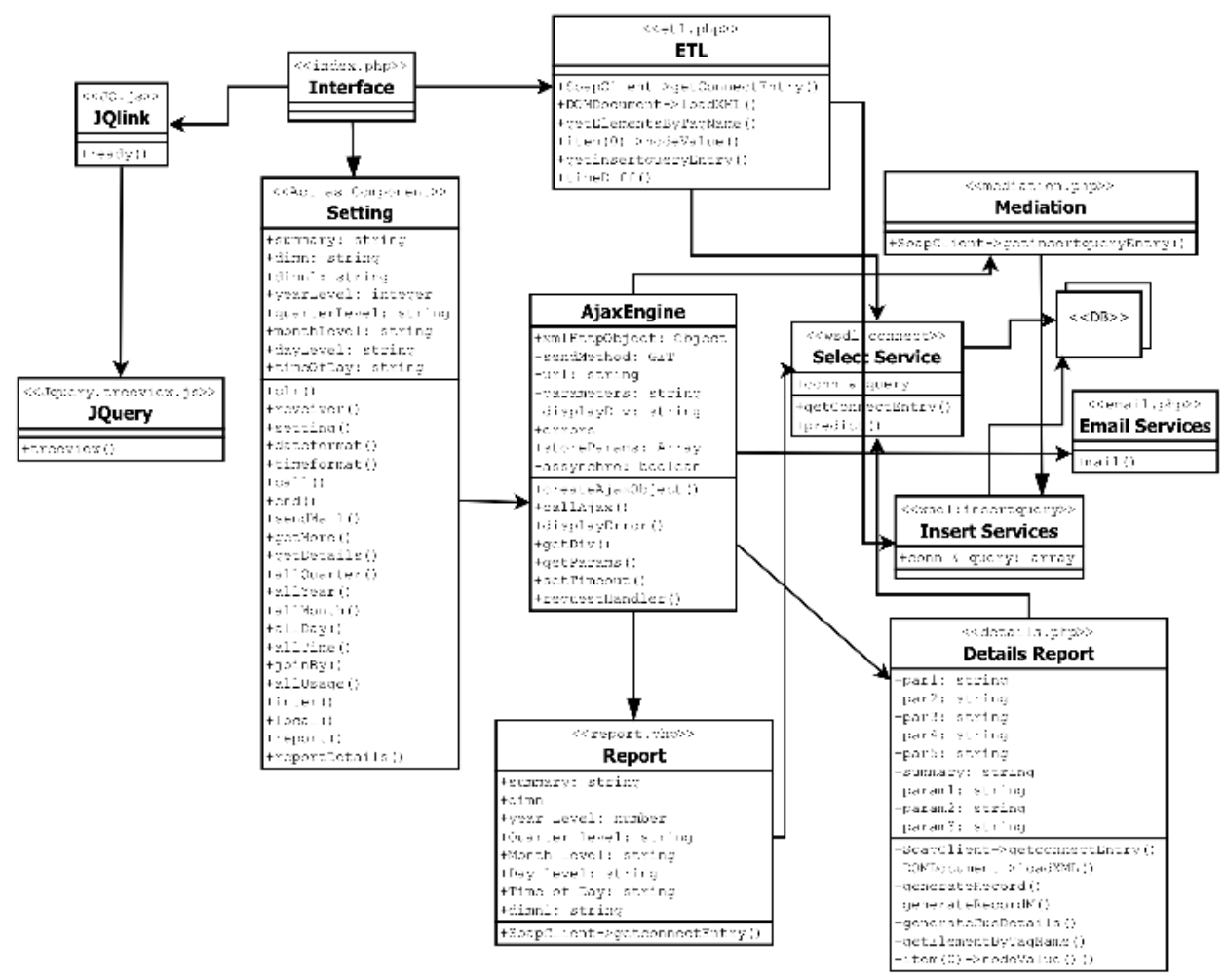

Fig. 6. Class diagram of the SOBI prototype simulator 


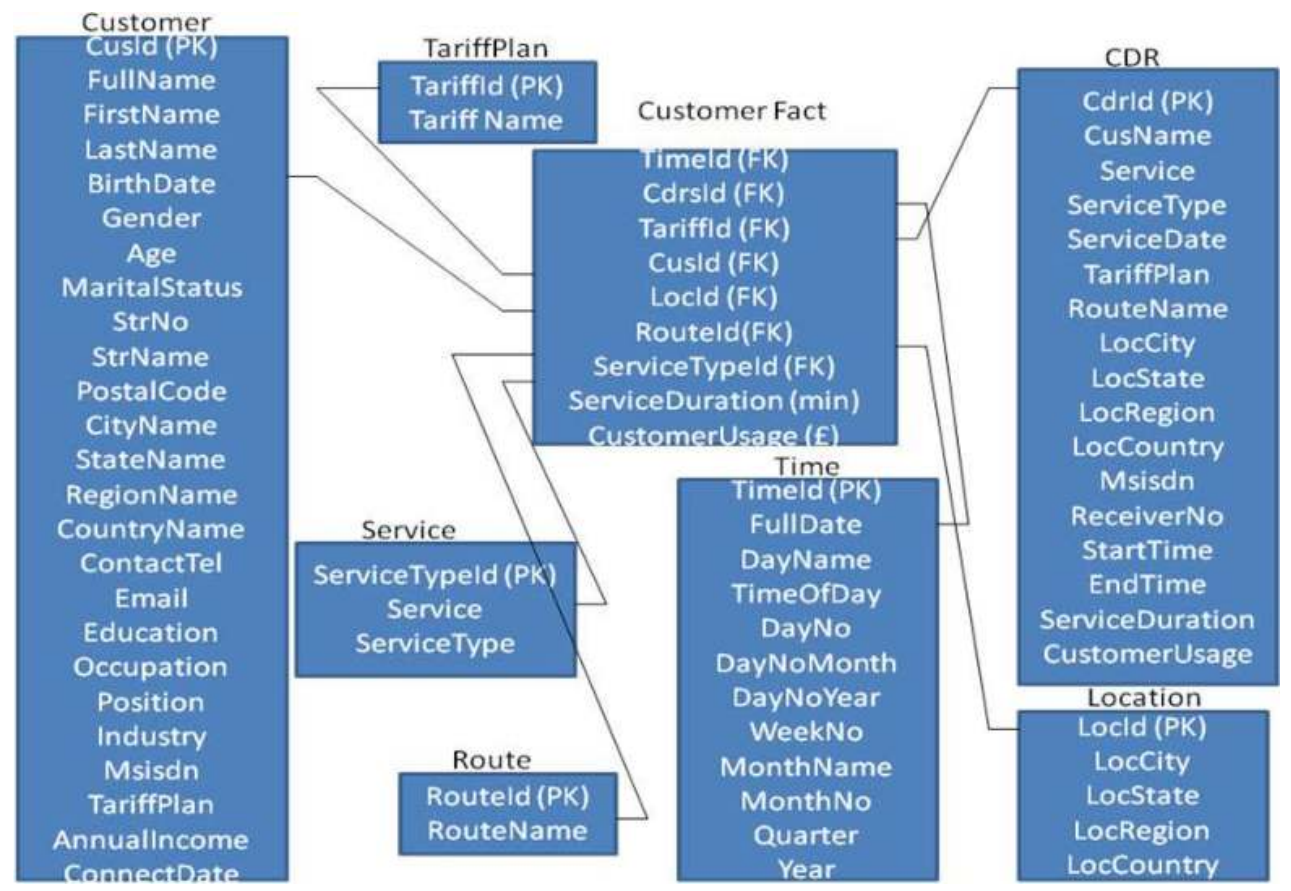

Fig. 7. Star Schema of Customer Fact.

As shown from Figure 7 above, the Customer Fact is in the centre surrounded by the dimension table. The time dimension will make it easy to view ServiceDuration and CustomerUsage on daily, weekly, monthly, quarterly and yearly basis. Other physical layer designs included data marts, metadata, backup and recovery, data aggregation, etc.

\subsection{Prototype implementation}

The implementation of SOBI prototype is divided into Data Source, DWs, analytical and presentation tools.

The simulator prototype was implemented using service-oriented technologies. As shown in Figure 6, the prototype has a single interface using JavaScript at the client side to capture the request of the user and pass it to the Ajax Engine which then send the request to the server where the WS class component are located. The ETL processes are being handled by etl.php. The index.php is the interface to invoke the ETL process and the interface will refresh to reflect the newly loaded data. The interface has a tree view menu list elements that is dynamically handled using the JQuery class. Setting.js acts as a listener to every change that occurs and passes the necessary parameter to the Ajax.class.js, which sends the request to the server and handles the response, which is display on the client side. Other components of the class diagram are discussed below. 
The Insert Service has a WSDL, which specified the input and output parameter operations. The array of input parameter contains the host, username, password, database, table, and query. This service is used to insert CDR data generated by the call simulator into the OSS database on MySQL server and is also used to load the transformed data into DW in another MySQL database on the same server. This class has also been developed to connect with PostgreSQL. This is the usefulness of SOBI, the interoperability and the reusability and flexibility that WS brings.

The select service also has WSDL and WS server class that perform the requested operation. The select service has input parameter as an array, which contains the same content as insert service and another additional parameter, which specified what type of string to be returned by the service. The service can return XML or HTML string depending on the expected result output. The HTML string has been specially developed to generate html table of any column and row without knowing the structure of the table. What is requires is the correct query. Similarly, XML file is generated using DOMDocument object class. The select service also has a function that calculates single exponential smoothing technique. This function takes the row of average usage query result accordingly and applies the formula to forecast the next average usage.

The report has been implemented using the select service to select from the database and send the return HTML string from the select service to Ajax Engine which passes it to JavaScript which is using DOM Objects to display the table in a specified div (cont) in the index.php corresponding to the specified of the interface report area. The report service contain series of next if statement which determines what query to be executed before invoking the select service. The details report could have been part of Report Service discussed above but it has been move to another PHP file for simplicity, readability and to avoid confusion as a result of the complexity of the if statement involved in both reports. Parameters sent by the Ajax is also examined to determine which query is required and responses returned from Select Service is handle using DOMDocument to load the XML string and generate html table which is sent back to the Ajax Engine.

Mediation Service get all the call simulator parameter sent by setting.js through Ajax Engine and invoke Select Service to get other information such as customer id of the caller and tariff plan. It has functions that calculate the duration and bill the customer before invoking Insert Service to insert the CDR data into the OOS database.

The extract, transform, and load services, which have been design separately during the SOBI system design, are now implemented together as a single service. The Select Service was invoked to select the current data from the source system and transformation process was carried out before invoking the Insert Service to load into the DW. During data transformation, the content of DW table was compare with sources in order to select the current information. PK and FK relationships are used to get the actual data from the sources system. The dimension and fact table was loaded during the ETL.

The Email Service gets the necessary parameter such as message, receiver email and name from client side through JavaScript and Ajax Engine. Email Service used PHP mail function to sent mail and returns nothing back to the Ajax Engine. 
The prototype was evaluated by developing a set of tasks that will enable telecoms analysts to perform customer call usage analysis through simulated calls and whether or not they could make informed decisions about specific customer. The evaluation was carried out by the telecom analysts were interviewed during the requirements gathering stage. Evaluation results clearly indicates a great potential of using SOBI in telecoms industry.

\section{Conclusion}

This chapter presents an investigation into the integration and analysis of data from CRM and CDR of Telecoms operators using SO approach to assist the organization in making real-time and accurate decision about the customer tariff plan to ensure customer satisfaction which in return can lead to increase in profit.

The prototype was evaluated against the potential outcome of the research study. The SOBI architecture and design was able to achieve all but the prototype has not been able to achieve everything. Analytic events on CDR, ability to offer the right product to the right customer, and security of WS have not been achieved. This is due to limitation of the prototype scope and it is expected that the prototype will have to go through next iteration of the software engineering process.

Telecoms operator cannot do without SOBI in the competitive market and ability to analyze, make decision, and act on the decision in time could be an advantage to exploit market opportunity. SOBI architecture have been developed and designed to achieve this but the prototype have not been able to evaluate everything about SOBI. Therefore, we need to implement other aspect and re-evaluate the SOBI architecture and design.

\section{References}

Atre, S. (2008), Successful Business Intelligence: Secrets to Making BI a Killer App, the McGraw-Hill Companies, ISBN: 978-0-07-149851-7, Available at

http:/ / books.google.co.uk/ accessed [19 July 2010].

Atre, S. (2003), The Top 10 Critical Challenges for Business Intelligence Success, White Paper Article, Available at

http://www.computerworld.com/computerworld/records/images/pdf/BusIntel lWPonline.pdf accessed [19 July 2010].

Berthold, H., Rosch P., Zoller S., Wortmann F., Carenini A., Campbell S., Bisson P., and Strohmaier F. (2010), An Architecture for Ad-Hoc and Collaborative Business Intelligence, ACM Conference Proceeding Series Vol. 426, Proceeding of the 2010 EDBT/ICDT Workshops, Lausanne, Switzerland, ISBN:978-1-60558-990-9, Article No. 13, Available at http:// portal.acm.org/citation.cfm accessed [28 June 2010].

Christensen, E., Curbera, F., Meredith, G., and Weerawarana, S. (2001), Web Services Description Language (WSDL) 1.1, W3C, Available at http://www.w3.org/TR/wsdl, accessed [5th August 2010].

Chung, W. and Chen, H. (2009), Handbooks in Information Systems Series: Business Computing, Volume 3, Edited by Gediminas, A. and Alok, G.,Emerald Group Publishing Limited, ISBN:978-1-84855-264-7, Available at 
http:/ / books.google.co.uk/books accessed [14 June 2010] , pp. 373-396.

Cunningham, C., Song, L., and Chen, P.P. (2004), Data Warehouse Design to support Customer Relationship Management Analyses, Data Warehousing and OLAP, Proceedings of the 7th ACM international workshop on Data warehousing and OLAP, Washington DC, USA, ISBN: 1-58113-977-2, pp. 14-22, Available at http:// portal.acm.org accessed [8th July 2010].

Gordon, S., Grigg, R., Horne, M., and Thurman, S. (2006), Service-Oriented Business Intelligence, Microsoft, Available at http://msdn.microsoft.com/enus/library/bb245659.aspx accessed[18 June 2010].

Griffin, J. (2003), A Challenge for the Telecom Industry: Converging Enterprise Portals and Business Intelligence to Produce a Collaborative Business Platform, Information Management Magazine, August 2003, Available at http://www.informationmanagement.com/issues/20030801/7154-1.html accessed [6th July 2010].

Hadden, J., Tiwari, A., Roy, R., and Ruta, D. (2007), Computer assisted customer churn management: State-of-the-art and Future Trends, Computers and Operations Research vol.34, No.10, pp2902-2917

Han, J., and Kamber, M. (2006), Data Mining : Concepts and Techniques, Morgan Kaufmann, Second Edition, ISBN:1-55860-901-6.

$\mathrm{Hu}$, J., Khalil, I., Han, S., and Mahmood, A (2011). Seamless integration of dependability and security concepts in SOA: A feedback control system based framework and taxonomy. Journal of Network and Computer Applications Vol 34(4), July 2011, pp1150-1159

Hung, S.Y, Yen, D.C, and Wang, H.Y. (2006), Applying Data Mining to Telecom Churn Management, Expert Systems with Application Vol.31, Issue 3, pp. 515-524, available at linkinghub.elsevier.com/retrieve/pii/S0957417405002654, accessed [2nd July 2010].

Hwang, H., Jung, T., and Suh, E.(2004), An LTV model and customer segmentation based on customer value: a case study on the wireless telecommunication industry, Expert Systems with Application Vol.26, Issue 2, pp.181-188, Available at http://www.sciencedirect.com/science accessed[8th July 2010].

Ishaya, T., Chadband, J., and Grierson, L. (2007), Integrating Enterprise Data for Decision Support in Construction Organisations, Proceedings of the 9th International Conference Organisations Systems , Funchal, Madeira, Portugal, ICEIS(1) : 534-539.

Ishaya, T., and Rigneau, J. (2007), Data Quality for Effective E-Commerce Customer Relationship Management, Proceedings of the 9th International Conference on Enterprise Information Systems, Funchal, Madeira, Portugal, ICEIS (4): 92-100.

Johnstone, D., and Wong, C.Y. (2008), Billing Audit on a Mobile Operator-Call Detail Record, Information Systems Control Journal, Vol. 3.

Kudyba, S. and Hoptroff, R. (2001), Business Intelligence A Guide to Productivity, Idea Group Publishing, ISBN: 1-930708-03-3, Available at http://www.igi-global.com accessed [14 June 2010].

Kleinbaum, D.G, Kupper, L.L, Nizam, and Muller, K.E. (2008), Applied regression analysis and other multivariable methods, Fourth Edition, ISBN: 13:978-0-495-38496-0. Available at http:/ / books.google.co.uk/ accessed [12 July 2010]. 
Kulkarni, U., Power, D. J. and Sharda, R. (2007), Decision Support for Global Enterprises: Annals of Information Systems, Vol. 1, Springer, Available at http://www.springerlink.com/content/g02v70027227648u/fulltext.pdf accessed [15 June 2010].

Lee, J.H., and Park, S.C.(2005), Intelligent profitable customers segmentation system based on business on business intelligence tools, Expert Systems with Application Vol.29, pp.145-152, Available at

http://www.sci.brooklyn.cuny.edu/ kopec/cis718/fall_2005/sdarticle2.pdf accessed[5th July 2010].

Levin, S. (2002), Lessons in CRM: when it comes to caring for customers, telecom firms need to wise up. Here's a primer of best practices, complied from a roster of CRM experts - Telecom Corporate, Telecom Asia, Available at http://findarticles.com/p/articles/mi_m0FGI/is_10_13/ai_94010195/, accessed [8th July 2010].

Madnick, S.E, Lee, Y.W, and Zhu H. (2009), Overview and Framework for data and Information quality research, ACM Journal, Data Information Quality 1(1)

MetaGroup, (2004), Data Mining Tools: METAspectrunSM Evaluation, Available at http://www.oracle.com/technology/products/bi/odm/pdf/odm_metaspectrum _1004.pdf accessed [30 July 2010].

Moss, L.T., and Atre, S. (2003), Business Intelligence Roadmap: The Complete Project Lifecycle for Decision-Support Applications, Addison-Wesley, ISBN: 0-201-784203.

Pareek, D. (2006), Business Intelligence for telecommunications, Auerbach Publications, ISBN: 0-8493-8792-2.

Patrick, P. (2005), Impact of SOA on Enterprise Information Architectures, International Conference on Management of Data archive, Proceedings of the 2005 ACM SIGMOD International Conference on Management of Data, pp. 844-848.

Power, D., J. (2003), A Brief History of Decision Support Systems, version 2.8, DSSResources.COM, Available at

http://dssresources.com/history/dsshistoryv28.html accessed [15 June 2010].

Ranjan, J. (2009), Business Intelligence: Concepts, Components, Technique and Benefits ,Journal of Theoretical and Applied Information Technology, Vol.9, No.1, Available at http://www.jatit.org/volumes/research-papers/Vol9No1/9Vol9No1.pdf accessed on [26 July 2010].

Rus, V.R., and Toader, V. (2008), Business Intelligence for hotels' Management Performance, International Journal of Business Research, FindArticles.com, Available at http://findarticles.com/p/articles/mi_6773/is_4_8/ai_n31136506/ accessed [14 June 2010].

Schnjakin, M., Menzel M., and Meinel C. (2009) , A pattern-driven security for serviceoriented architectures, Conference on Computer and Communications Security, Proceeding of the 2009 ACM workshop on Secure web services, Chicago, Illinios, USA, ISBN:978-60558-789-9, pp. 13-20, Available at http:// portal.acm.org/citation.cfm accessed [28 June 2010]. 
Watson, H.J. (2005), Real Time: The Next Generation of Decision Support Data Management, Business Intelligence Journal, Vol. 10, No.3, pp. 4-6.

Weiss, G.M. (2004), Data Mining in Telecommunications, kluwer, 2004.

Witten, I.H, and Frank, E. (2005), Data Mining: Practical Machine Learning Tools and Techniques, Second Edition, ISBN: 0-12-088407-0, Available at http:/ / books.google.co.uk/ accessed [12 July 2010].

Wu, L., Barash, G. And Bartolini, C. (2007), A Service Oriented Architecture for Business Intelligence, IEEE International Conference on Service-Oriented Computing and Application (SOCA'07), Newport, Beach. 


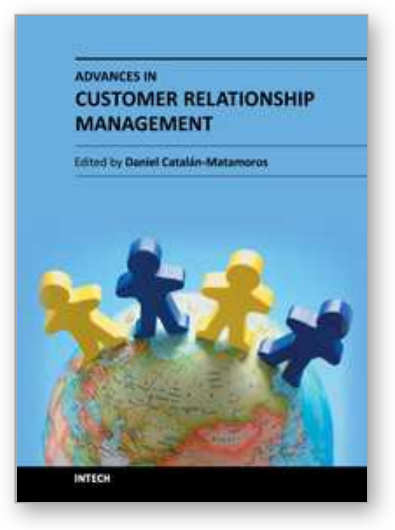

\author{
Advances in Customer Relationship Management \\ Edited by Dr. Daniel Catalan-Matamoros
}

ISBN 978-953-51-0516-9

Hard cover, 146 pages

Publisher InTech

Published online 11, April, 2012

Published in print edition April, 2012

Customer relationship management (CRM) strategies have become increasingly important worldwide due to changes in expectations from customers as well as changes in the nature of markets. This book puts forth a conceptualization that attempts to not only outline CRM's domain but also to reconcile the divergent perspectives found in the academic and popular literature. Readers can see through measurable datacontaining examples how the theory is applied with great success by various real-life examples. This book presents innovative proven methods for determining whether a CRM strategy for changing the way a company provides service (by adding new technology, processes, and procedures) will realize the return on the investment projected. It could be a great help to CRM personnel, student, managers and any one that works directly or indirectly with customers.

\title{
How to reference
}

In order to correctly reference this scholarly work, feel free to copy and paste the following:

Tanko Ishaya and Musiliudeen Folarin (2012). Business Intelligence in Telecoms Industry: A Service Oriented Approach, Advances in Customer Relationship Management, Dr. Daniel Catalan-Matamoros (Ed.), ISBN: 978953-51-0516-9, InTech, Available from: http://www.intechopen.com/books/advances-in-customer-relationshipmanagement/book-business-intelligence-in-telecoms-industry-a-service-oriented-approach

\section{INTECH}

open science | open minds

\author{
InTech Europe \\ University Campus STeP Ri \\ Slavka Krautzeka 83/A \\ 51000 Rijeka, Croatia \\ Phone: +385 (51) 770447 \\ Fax: +385 (51) 686166 \\ www.intechopen.com
}

\author{
InTech China \\ Unit 405, Office Block, Hotel Equatorial Shanghai \\ No.65, Yan An Road (West), Shanghai, 200040, China \\ 中国上海市延安西路65号上海国际贵都大饭店办公楼 405 单元 \\ Phone: +86-21-62489820 \\ Fax: +86-21-62489821
}


(C) 2012 The Author(s). Licensee IntechOpen. This is an open access article distributed under the terms of the Creative Commons Attribution 3.0 License, which permits unrestricted use, distribution, and reproduction in any medium, provided the original work is properly cited. 